\title{
NEW LINKAGE AND INDEPENDENCE DATA FOR RUBY AND JERKER IN THE MOUSE
}

\author{
MARGARET E. WALLACE \\ Department of Genetics, University of Cambridge
}

Received I I.i. 58

\section{INTRODUCTION}

Two comments have recently been made about the linkage relations of ruby $(r u)$ and jerker ( $j e)$ of linkage group XII of the house mouse. The earlier (Falconer, 1956) states that these factors "appear to segregate independently of each other in our stocks, though they showed linkage in the original data reported by Fisher and Snell (1948)". The later (Phillips, 1956), which reports a new addition (congenital hydrocephalus, ch) to linkage group XIV, records "a slight indication of linkage between $c h$ and jerker", and discusses the possibility that groups XIV and XII correspond to one chromosome. As there is doubt about the reality of group XII and thus also about its chromosomal relation with other groups it seems useful to make generally available two further bodies of data. One was obtained some years ago and has until now been published only in a somewhat inaccessible form (Wallace, 1954); the other is newer and has not yet been published at all.

\section{HISTORY OF NEW DATA}

The mice concerned in both the latter bodies of data were bred in this Department and were descended from those used by Fisher in 1948 which provided, with Snell's, the first data on ruby and jerker. Since their genealogical relationship may throw some light upon the paradoxes of the problem a brief history and a summary of their data are first set out.

Fisher and Snell's paper concerned their simultaneous and independent observation of an association between ruby and jerker. The data (table I) consist of intercrosses and backcrosses both in coupling and in repulsion. It was pointed out that nearly all the separate portions, both in Snell's and in Fisher's summaries favour linkage, and that the total compilation (comprising some 900 mice bred) shows a very significant deviation from 50 per cent. recombination $\left(\chi^{2}=7.22\right.$ for $\mathrm{I}$ d.f. $)$, with a combined recombination value of about 45 per cent. as derived by Fisher's scoring technique. Group numeral XII, the next available at that time, was assigned to these factors.

Despite the overall homogeneity there was one portion of the Cambridge summary, the repulsion data from segregating males, which did not favour linkage (as may be shown by its negative score 
at 50 per cent. recombination; the value from repulsion males and females together is 52.5 per cent.). The paper mentioned that the repulsion data were the last to be produced (by reason of the derivation of repulsion heterozygotes via preparation matings from the coupling), and that more data from repulsion backcrosses were still needed.

TABLE I

"Linkage" data: I. After outcross of ruje to line 3 in Cambridge 1947. II. After outcross of ru to je in Bar Harbor 1945

(Based on the table in Fisher and Snell, 1948)

\begin{tabular}{|c|c|c|c|c|c|c|c|c|c|c|c|}
\hline \multirow{2}{*}{\multicolumn{2}{|c|}{ Types of mating }} & \multicolumn{5}{|c|}{$\begin{array}{l}\text { I. Cambridge data } \\
\text { Phenotypes of progeny }\end{array}$} & \multicolumn{5}{|c|}{$\begin{array}{l}\text { II. Bar Harbor data } \\
\text { Phenotypes of progeny }\end{array}$} \\
\hline & & $+t$ & $r u$ & je & ruje & Total & ++ & $r u$ & $j e$ & ruje & Total \\
\hline \multicolumn{12}{|l|}{ Intercrosses : } \\
\hline Coupling & - & 147 & 43 & 53 & I9 & 262 & 4 & 2 & I & $\mathbf{I}$ & 8 \\
\hline Repulsion & . & - & - & - & - & - & 86 & 35 & 31 & 5 & I 57 \\
\hline \multicolumn{12}{|l|}{ Backcrosses : } \\
\hline Coupling $q$ & . & $5^{\mathrm{I}}$ & 30 & 48 & 44 & I 73 & 32 & $3^{I}$ & 30 & 47 & 140 \\
\hline Coupling o & . & I 7 & I 5 & I 2 & I 7 & $6 \mathrm{I}$ & 20 & I 3 & I 3 & I 4 & 60 \\
\hline Repulsion 우 & . & 4 & 6 & 4 & 4 & I 8 & - & - & - & - & - \\
\hline Repulsion o & . & 5 & 4 & 5 & 8 & 22 & - & - & - & - & - \\
\hline \multicolumn{2}{|c|}{$\begin{array}{l}\text { Recombination value. } \\
\text { Departure from } \\
\text { independence }\end{array}$} & \multicolumn{5}{|c|}{$\begin{array}{c}4^{6 \cdot 3^{1}} \text { per cent. } \\
\chi_{1}^{2}=2 \cdot 05 \quad 0.2>p>0 \cdot 1\end{array}$} & \multicolumn{5}{|c|}{$\begin{array}{c}42.17 \text { per cent. } \\
\chi^{2}{ }_{1}=6.55 \text { o.02 }>p>0.01\end{array}$} \\
\hline \multicolumn{12}{|c|}{ III. Combined data } \\
\hline \multicolumn{5}{|c|}{$\begin{array}{l}\text { Recombination value } \\
\text { Departure froin independence } \\
\text { Heterogeneity }\end{array}$} & \multicolumn{7}{|c|}{$\begin{array}{ll}\quad 44.74 \text { per cent. } & 0.01>p>0.001 \\
\chi^{2}{ }_{1}=7.22 & 0.3>p>0.2 \\
\chi^{2}{ }_{1}=1.37 & \end{array}$} \\
\hline
\end{tabular}

Further work on the association of ruby and jerker continued in this Department until the present time.

Fisher's I948 data concerned the segregation in 1947 of these factors immediately after their introduction to Line 3 of the $2 \mathrm{I}$ Segregating Inbred Lines, where they were combined with other factors. (These Lines had been set up by Fisher [1949a] to discern new linkages and to accumulate the large bodies of data needed to confirm-or to contradict-indications of loose linkage.) It is clear then that the data were from relatively outbred material : in fact there are only three sib matings and these are non-successive. In accordance with the strict sib mating policy subsequently followed in the Lines the next body of data is on the other hand very inbred (table 2).

This concerns the matings made up from January 1948 until July 1952 by Miss M. F. I. Speyer who became responsible for Line 3 . They cover some eight generations of inbreeding. It is not as large 
a body of data as the earlier one (some 640 mice were bred), but as it consists solely of backcrosses, it is equally informative-about 2600 units of Information. Although repulsion data are still in the minority this phase is now sufficiently well represented to balance the coupling. The striking feature here is that in contrast to the earlier data both phases fail to show linkage.

A little further data accumulated during the following year (1952-3), but it is not reported here because the ruby : normal ratio is heterogeneous as between matings and there is a serious depletion of jerkers. The Line became impossible to continue, more and more of the matings being infertile, and in July 1953 it had virtually died out.

TABLE 2

"Independence" data : from eight generations of inbreeding after the data for table I were obtained. Cambridge 1948-52

\begin{tabular}{|c|c|c|c|c|c|c|c|}
\hline \multirow{2}{*}{ Types of mating } & \multicolumn{5}{|c|}{ Phenotypes of progeny } & \multirow{2}{*}{$\begin{array}{c}\text { Recombination } \\
\text { value }\end{array}$} & \multirow{2}{*}{$\begin{array}{l}\text { Departure } \\
\text { from } \\
\text { independence }\end{array}$} \\
\hline & ++ & $r u$ & $j e$ & ruje & Total & & \\
\hline $\begin{array}{l}\text { Backcrosses : } \\
\text { Coupling } 9\end{array}$ & & & $E$ & & & & \\
\hline Coupling o & 53 & $\begin{array}{l}59 \\
63\end{array}$ & $\begin{array}{l}51 \\
49\end{array}$ & $\begin{array}{l}51 \\
45\end{array}$ & $\begin{array}{l}223 \\
210\end{array}$ & 52.58 per cent & $\chi^{2}{ }_{1}=0.9^{8}$ \\
\hline Repulsion o & 17 & 20 & 15 & 27 & 79 & 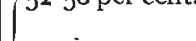 & $0.5>h>0.2$ \\
\hline Repulsion $\sigma^{*}$ & $3^{I}$ & 27 & 34 & 35 & 127 & & \\
\hline
\end{tabular}

The figures here are slightly smaller than those given earlier (Wallace, 1954) because the earlier compilation included in error some data from the outbred material.

To preserve the combination of factors in the Line, two outcrosses were then made to another inbred stock, and from their descendants a new Line was formed by Mrs M. A. C. MacNeil. The first matings segregating for ruby and jerker were intercrosses. From these and their descendants came known repulsion backcrosses and backcrosses whose linkage phase was unknown; and from these in turn came known coupling backcrosses. Their pedigree covers about six generations from the outcross, the last mating breeding early in 1956 . While each generation was more inbred than the previous one, only the last three were sib mated. The material is similar in genealogical origin to that of Fisher, being relatively outbred, and it is in strong contrast with the 1948-52 material which was much more inbred.

Table 3 summarises the known coupling and repulsion data. The intercrosses are omitted because the ruby : non-ruby and jerker : nonjerker ratios are seriously disturbed; and the backcrosses of uncertain phase are also omitted, for obvious reasons. In the remaining data, ruby is somewhat inviable but as the jerker ratios do not deviate significantly from expectation, there is no disturbance to linkage and the usual process of scoring is a sufficiently accurate way of determining the amount and significance of deviation from independent assortment. 
The important feature here is that, as in the 1947 data, and in contrast to the $1948-52$, linkage is favoured. Of the three, this is the smallest body of data (some 8I mice were bred, giving 339 units of Information). The estimated linkage value is close to the 1947 one, about 40 per cent. The repulsion data, as in the 1947, show weaker linkage than do the coupling and it is unfortunate that no more data are available.

In $195^{6}$, before the reappearance of linkage had been noticed, Line 3 was terminated and the factors contained in it used elsewhere.

TABLE 3

"Linkage" data : from matings following an outcross. The outcross was made after the data in table 2 were obtained. Cambridge 1954-56

\begin{tabular}{|c|c|c|c|c|c|c|c|}
\hline \multirow{2}{*}{ Types of mating } & \multicolumn{5}{|c|}{ Phenotypes of progeny } & \multirow{2}{*}{$\begin{array}{l}\text { Recombination } \\
\text { value }\end{array}$} & \multirow{2}{*}{$\begin{array}{c}\text { Departure } \\
\text { from } \\
\text { independence }\end{array}$} \\
\hline & ++ & $r u$ & je & ruje & Total & & \\
\hline $\begin{array}{c}\text { Backcrosses : } \\
\text { Coupling } 9 \\
\text { Coupling } 0 \\
\text { Repulsion } 9\end{array}$ & $\begin{array}{r}15 \\
4 \\
8\end{array}$ & $\begin{array}{l}5 \\
1 \\
8\end{array}$ & $\begin{array}{r}I I \\
2 \\
I I\end{array}$ & $\begin{array}{l}9 \\
2 \\
5\end{array}$ & $\begin{array}{r}40 \\
9 \\
32\end{array}$ & $39 \cdot 53$ per cent. & $\begin{array}{c}\chi^{2}{ }_{1}=3.4 \mathrm{I} \\
0.1>p>0.05\end{array}$ \\
\hline
\end{tabular}

\section{THE DATA FROM EDINBURGH}

Mice carrying ruby and jerker, derived from Fisher's I 947 material, were sent to Dr Falconer and used to obtain further data (1956). He has kindly supplied me with a compilation and the following information. All the material is outbred. Crosses were made of ruby jerker animals to normals from eight unrelated sources; $F_{1}$ from three of the outcrosses were intercrossed, providing coupling intercross data, and $F_{1}$ females from six of the outcrosses were backcrossed to males of the ruby jerker stock, providing coupling backcross data (table 4). The recombination value from the intercrosses is estimated as $48 \cdot 1067$ per cent. and that from the backcrosses as $5 \mathrm{I} \cdot 3803$ per cent. The

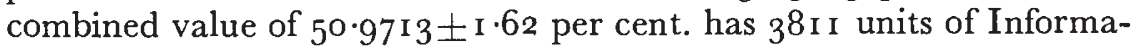
tion, slightly more than were given by any of the earlier bodies of data.

A closer analysis of the more informative material, the backcrosses, reveals no significant heterogeneity in the ratio of non-recombinants to recombinants between the groups of matings from the six sources $(p=0.5$ to 0.3$)$. There is, however, a discrepant ratio, I6:33, from females derived from one outcross mating : it gives a recombination value of 67.3 per cent. and a $\chi^{2}$ of 5.8980 for I d.f.; but no such anomaly is seen in the females from a second outcross to the same stock, and this single observation is not sufficiently large to produce overall heterogeneity. The intercross data also, when grouped according to their three sources, appear to be homogeneous. 


\section{ANALYSIS OF THE TOTAL DATA}

It should perhaps be noted that the single-factor ratios in all the bodies of data now given conform to expectation (except in the Cambridge $1954^{-5} 6$ data where only one of them is disturbed). There is therefore no question of bias in the estimates of linkage due to viability disturbance. If there were, it would be desirable to have about equal amounts of coupling and repulsion data, at least in the backcrosses : in fact, there are very little repulsion data. Although this unbalance is not important from the point of view of linkage estimates, it is a regrettable weakness in the foundation upon which hypotheses other than linkage may have to be erected.

Clearly the data are not consistent in the linkage values they yield.

TABLE 4

"Independence" data : from matings following outcrosses of ruje mice derived from Cambridge in 1947. Edinburgh 1956

\begin{tabular}{|c|c|c|c|c|c|c|c|}
\hline \multirow{2}{*}{ Types of mating } & \multicolumn{5}{|c|}{ Phenotypes of progeny } & \multirow{2}{*}{$\begin{array}{l}\text { Recombination } \\
\text { value }\end{array}$} & \multirow{2}{*}{$\begin{array}{c}\text { Departure } \\
\text { from } \\
\text { independence }\end{array}$} \\
\hline & ++ & $r u$ & je & ruje & Total & & \\
\hline $\begin{array}{l}\text { Intercrosses: } \\
\text { Coupling }\end{array}$ & $15^{8}$ & 53 & 44 & 17 & 272 & & $\chi^{2}{ }_{1}=0.04$ \\
\hline $\begin{array}{c}\text { Backcrosses : } \\
\text { Coupling } q\end{array}$ & 209 & 224 & 204 & 196 & 833 & $5^{\circ} \cdot 97$ per cent. & $0.9>p>0.8$ \\
\hline
\end{tabular}

It may be supposed that environmental factors such as temperature and diet are the cause of fluctuation in chiasmata frequency between the two loci. This possibility cannot easily be excluded, for even within one laboratory there may be unsuspected changes over a long period of time, but it is safe to say that there have been no obvious ones in Cambridge, yet the Cambridge data are significantly heterogeneous. This is apparent from the following calculation. If the estimated recombination values for the 1947 , the $1948-52$ and the 1954-56 material are designated $\hat{\theta}_{1}, \hat{\theta}_{2}$ and $\hat{\theta}_{3}$ respectively, with Information parameters $I_{1}, I_{2}$ and $I_{3}$ respectively, a combined estimate, $\hat{\theta}$, may be obtained from the formula

$$
\hat{\theta}=\frac{\mathrm{I}_{1} \hat{\theta}_{1}+\mathrm{I}_{2} \hat{\theta}_{2}+\mathrm{I}_{3} \hat{\theta}_{3}}{\mathrm{I}_{1}+\mathrm{I}_{2}+\mathrm{I}_{3}}
$$

This is $49 \cdot 047^{6}$ per cent. The formula gives a weighted mean to $\hat{\theta}$ and leads to the $\chi^{2}$ formula

$$
\chi_{2}^{2}=\mathrm{I}_{1} \hat{\theta}_{1}^{2}+\mathrm{I}_{2} \hat{\theta}_{2}{ }^{2}+\mathrm{I}_{3} \hat{\theta}_{3}{ }^{2}-\left(\mathrm{I}_{1}+\mathrm{I}_{2}+\mathrm{I}_{3}\right) \hat{\theta}^{2}
$$

which is thus an appropriate test of heterogeneity. At 6.3488 for 2 d.f. it is significant, $p$ being between 0.05 and 0.02 .

It is interesting that the combined $\hat{\theta}$ is virtually 50 per cent. Further, when the Bar Harbor 1947 and Edinburgh $195^{6}$ values are 
included in the formula (see below), the combined $\hat{\theta}$ remains at almost exactly the same value, $49 \cdot 0470 \pm \mathrm{I} \cdot 4739$ per cent.

\begin{tabular}{|c|c|c|c|c|}
\hline \multicolumn{3}{|c|}{ Cambridge } & Bar Harbor & Edinburgh \\
\hline I 947 & I $948-52$ & I $954-56$ & 1947 & I956 \\
\hline $\begin{array}{c}46 \cdot 4310=\hat{\theta}_{1} \\
1606 \cdot 4{ }^{2} 6=I_{1}\end{array}$ & $\begin{array}{l}5^{\mathrm{I} \cdot 95^{6} \mathrm{I}}=\hat{\theta}_{2} \\
255^{6} \cdot 09=\mathrm{I}_{2}\end{array}$ & $\begin{aligned} 39 \cdot 5259 & =\hat{\theta}_{3} \\
339 \cdot 343^{2} & =I_{3}\end{aligned}$ & $\begin{array}{r}42 \cdot \mathrm{I} 7 \mathrm{OO}=\hat{\theta}_{4} \\
\mathrm{I} 066 \cdot 68=\mathrm{I}_{4}\end{array}$ & $\begin{array}{r}50 \cdot 9713=\hat{\theta}_{5} \\
3^{810 \cdot 6033^{2}}=\mathrm{I}_{5}\end{array}$ \\
\hline
\end{tabular}

These values used in the $\chi^{2}$ formula, give even more significant heterogeneity, for $\chi^{2}$ for 4 d.f. is 12.8023 with $p$ between 0.02 and $\mathrm{o} \cdot \mathrm{O}$ I.

\section{DISCUSSION}

It is perhaps a platitude that the results of later work do not diminish the significance of the earlier. It is, however, sometimes salutary to restate it, especially in conjunction with a further one, namely that the establishment of independence is not proof of localisation on different chromosomes. The reality of linkage group XII is not disproved, but the manifest heterogeneity within the data requires an explanation in terms of linkage ; or, if this is not found possible, a search must be made for other hypotheses and a discriminating experiment designed.

The possibility of environmental disturbance to linkage has been mentioned. Such factors as temperature and age are well-known to affect linkage values in Drosophila. The absence of records of such effects in mice is probably due to the general lack of sufficiently accurate linkage data in which they may be discerned. There are two experiments where the design envisaged this kind of analysis and where an age effect was found (Fisher, I949b, and Wallace, 1957), and it is now recognised that if experimental work allows of its observation, sex differences in recombination are very commonly found. It is conceivable that loose linkages, particularly those that span the centromere, are very susceptible to these and to other as yet unknown environmental agents.

That this may be true of genetic agents is not so evident : for there are no recorded instances in mice-as there are in Drosophila and other organisms - of spontaneous translocation and inversion, or of mutations specifically increasing or decreasing the amount of recombination. This again may be due to the lack of careful experimentation. The presence of such phenomena in other organisms should suggest, until it is proved otherwise, that their existence is possible in mice. Indeed, heterogeneous data provide the first kind of evidence which should be sought, and it is unfortunate that there is probably a tendency to withhold such data from publication because the cause of heterogeneity 
has not been investigated. Finally, artificial selection has been known to decrease and to increase recombination in certain organisms (e.g. Matthiola, see Fisher, 1933); moreover, inbreeding has also been known to change the properties of chiasma formation, usually reducing the frequency (Rees and Thompson, I956). These observations point to the existence of minor genetic agents having a cumulative effect; the lack of experimental work on this point in mice leaves open the possibility of their existence.

The present data do not allow of the isolation of any one of these possible causes of heterogeneity. However, it may be noted that there are two striking features which throw doubt on the hypothesis of linkage itself. First, the data as a whole favour independence. Secondly, the three * sections which significantly contradict independence arose from outbred material: this conflicts with the view that the lower linkage values are due to the fortuitous accumulation of genetic factors tending to tighten linkage, for these are more likely to be dispersed by outbreeding than to be maintained by it.

Here again, it is perhaps useful to restate a further platitude: that such dispersion is expected because outcrossing promotes heterozygosity and breeding from outcrossed material produces segregation. For this suggests an alternative hypothesis : affinity (Michie, I953, and Wallace, 1953). Outcrossing may be expected to result in heterocentricity and inbreeding in homocentricity. To state this more precisely : Quasi-linkage of two factors may be supposed to be due to their proximity to centromeres on different chromosomes, the centromeres being capable of showing preferential association at meiosis. Inbreeding is always expected to result in homocentricity; in this case, quasi-linkage disappears. Outbreeding is expected to result either in homocentricity or in heterocentricity ; if heterocentricity results, quasi-linkage reappears. Outbreeding will result in homocentricity if the two stocks concerned in the outcross have the same centrotypes for the chromosomes marked by the two factors, and it will result in heterocentricity if they have different centrotypes. These and related points have been explained fully in a recent paper (Wallace, I958, p. 217-18). It is sufficient to notice here.that none of the present bodies of data conflict with these expectations : for the inbred section shows independence, three of the outbred sections show a linkage-like association and one of them shows independence.

Closer examination of these bodies of data reveals a closer fit to expectation on an affinity hypothesis. Firstly, the repulsion data in the Cambridge 1947 compilation is from slightly more inbred material than the coupling; the weakness of the linkage it shows may be interpreted as a result of the inbreeding. Secondly, the Bar Harbor coupling matings are slightly more inbred than the repulsion intercrosses (private communication), and give data showing

* These are the Cambridge 1947 and $1954-56$, and Bar Harbor 1945 data. That the latter are outbred is confirmed by Snell (private communication). 
weaker linkage than the repulsion (see table $I$ : the recombination values are about 43 and 37 per cent. respectively).

Thirdly, a heterogeneity test of the Cambridge 1948-52 inbred data, while formally exhibiting homogeneity $(p$ is 0.2 to $0 \cdot 1)$, discloses the fact that three of the twenty-three $\chi^{2}$ values contributing to the total $\chi^{2}$ have probabilities less than 0.05 : these are $\chi^{2}$ values of $4 \cdot 7647,5 \cdot 555^{6}$, and $7 \cdot 75^{86}$. Some degree of heterogeneity is not unexpected since this stock represents progressive inbreeding and not all matings can be expected to be homocentric at once : that is, the stock should be expected to consist mainly of matings showing independence and partly of matings showing deviations from 50 per cent. In fact, the segregation giving $\chi^{2}=4.7647$ gives a value less than $5^{\circ}$ per cent., and the other two a value exceeding $5^{\circ}$ per cent. A linkage hypothesis cannot tolerate for the same factors values both less than and greater than 50 per cent., but an affinity one can. (Segregations giving values exceeding 50 per cent., i.e. "reversals", arise from heterozygotes in which the maternal centromere of one pair of homologous chromosomes associates at meiosis with the paternal centromere of the other pair of homologues and vice versa.)

Finally, the Edinburgh 1956 outbred material (which showed independence) reveals a similar situation. As has been stated, eight different stocks were used in the outcrosses. It is reasonable to expect that by chance some of these should have resulted in quasi-linkage and others not, whereas the apparent homogeneity of the data $(p=0.5$ to 0.3 ) suggests that there were no quasi-linkages. However there is one significantly discrepant segregation (that giving a recombination value of 67.3 per cent.), and this does at least suggest that the outcross stock concerned was of a different centrotype from the ruby jerker stock. The second outcross to it did not reproduce the quasi-linkage, but this may have been due to heterocentricity in one or both chromosomes in the ruby jerker stock (which was not closely inbred).

The interpretation to be made of the results of these heterogeneity tests depends on the meaning of "formal significance". Perhaps a fourth platitude may be excused here on account of its relevance. Lack of significance at the 5 per cent. level does not necessarily disprove heterogeneity - the progeny numbers in the individual matings and sets of matings, and the occasional deviations from 50 per cent. due to quasi-linkage, may both be too small to produce a heterogeneity $\chi^{2}$ significant at that level. In the present case this is very likely so, for the recombination values for ruby and jerker so far encountered have been, in general, very loose (40 per cent. or higher), and the progeny numbers from each set of matings (Edinburgh, 1956) average I 19 and from each mating (Cambridge, 1948-52) average 24. It is therefore probably true to say that the amount of heterogeneity exhibited by these two bodies of data is about as much as should be expected.

To sum up : Quasi-linkage is expected to occur in some, but not 
necessarily in all, outcross bodies of data, and to be absent in inbred ones. Both expectations are fulfilled. Further, the results of internal analysis definitely favour affinity rather than linkage. However, linkage is not an untenable hypothesis because the existence of factors capable of causing fluctuation in the recombination value cannot be excluded.

Evidence which may be sought experimentally to distinguish between these two phenomena is of several kinds. For example, a further outcrossing programme might result in the renewed observation of values significantly exceeding $5^{\circ}$ per cent. If any of this material showed linkage values less than 50 per cent. it could be manipulated so as to produce (if affinity were operating) animals capable of giving values exceeding 50 per cent. Further repulsion data could also be produced and would be informative. Tests of linkage of ruby and jerker, simultaneously with factors in other linkage groups and thus likely to be on other chromosomes, might result in the establishment of non-linear linkage relations between them: according to what these were, it might then be possible to conclude either that ruby and jerker are linked and to locate the centromere in relation to them, or that they are not linked and to define the maximum distance of each from its own centromere. (These ideas have been developed elsewhere : Wallace, 1958). Unfortunately, although one of Phillips' experiments with congenital hydrocephalus did involve ruby and jerker simultaneously (private communication), her data show severe viability disturbance and the estimated recombination values are insignificantly below 50 per cent., so that no realistic conclusion can be drawn.

It is possible that other cases of heterogeneous linkage data may be explained on the basis of affinity. One case of non-linearity of the linkage relations between three markers has been thoroughly investigated and shown to be fully explicable on this basis (Wallace, I958). The disappearance of an association on inbreeding, the observation of anomalous linkage relations, and the discovery of heterogeneity are likely to have led to the abandonment of data without publication. It would be of considerable interest if such cases were published and others searched for in past records.

\section{SUMMARY}

Two new bodies of data from Cambridge on the association of ruby and jerker in the mouse are made available. One shows independent segregation and the other linkage. All the evidence on record is reviewed and discussed. Interpretations based on linkage and on affinity aregiven, and the design of discriminating experiments sketched.

Acknowledgments.-I am indebted to Sir Ronald Fisher, Miss M. F. I. Speyer and Mrs M. A. C. MacNeil for permission to use the data in this Department 
(hitherto unpublished) and to Dr D. S. Falconer for permission to analyse the data published briefly in Mouse News Letter.

\section{REFERENCES}

FALCONER, D. S. I956. Mouse News Letter, 15, 24.

FISHER, R. A. 1933. Selection in the production of the ever-sporting stocks. Annals of Botany, 47, 727-733.

FISHER, R. A., AND SNELL, G. D. I 948 . A twelfth linkage group of the house mouse. Heredity, 2, $27 \mathrm{I}-273$.

Fisher, R. A. 1949a. The Theory of Inbreeding. Oliver and Boyd, London.

FISHER, R. A. I $949 b$. A preliminary linkage test with agouti and undulated mice. Heredity, 3, 229-24I.

MICHIE, D. I953. Affinity: a new genetic phenomenon in the house mouse. Nature, $I 7 I, 26-27$.

PHILlips, R. J. S. I956. The linkages of congenital hydrocephalus in the house mouse. F. Hered., 47, 302-304.

REES, H., AND THOMPSON, J. B. I956. Genotypic control of chromosome behaviour in rye. 3. Chiasma frequency in homozygotes and heterozygotes. Heredity, ro, $4 \mathrm{I} 0-424$.

WAllACE, M. E. 1953. Affinity : a new genetic phenomenon in the house mouse. Nature, ${ }^{7} 7$ I, 27-28.

wallace, M. E. 1954. Studies in Mouse Genetics. Ph.D. Dissertation. Cambridge University Library.

WALLACE, M. E. 1957. A balanced three-point experiment for linkage group V of the house mouse. Heredity, II, 223-258.

WALLACE, M. E. 1958. Experimental evidence for a new genetic phenomenon. Phil. Trans. Roy. Soc. B, 24I, 21 I-254. 